\title{
Composite multiscale mechanics for composite enhanced concrete structures
}

\author{
C. C. Chamis ${ }^{1} \&$ P. K. Gotsis ${ }^{2}$ \\ ${ }^{I}$ NASA Glenn Research Center, Cleveland, Ohio, USA \\ ${ }^{2}$ Technical Education Institute, TK62124, Serres, Greece
}

\begin{abstract}
A new and effective method is described for designing composites to repair damage or enhance the overload strength of concrete infrastructures. The method is based on composite mechanics, which is available in computer codes. It is used to simulate structural sections made from reinforced concrete, which are typical in infrastructure, as well as to select reinforced concrete structures. The structural sections are represented by a number of layers through the thickness where different layers are used in concrete, and for the composite. The reinforced concrete structures are represented with finite elements where the element stiffness parameters are from the structural sections, which are represented by composite mechanics. The load carrying capability of the structure is determined by progressive structural fractural. Results show improvements of up to $40 \%$ for damage and for overload enhancement with relatively small laminate thickness for the structural sections and up to three times for the composite enhanced select structures (arches and domes).
\end{abstract}

Keywords: arches, domes, finite element, composite mechanics, displacements, stresses, buckling modes, vibration modes.

\section{Introduction}

Reinforced concrete is widely used in the construction industry. Concrete tends to crack, chip and be damaged as a result of inadvertent loads or overloads that may not have been accounted for in the initial design. The damage in concrete structures may extend to a state where the safety of that structure becomes a major concern. Recently, considerable effort has been expended on repairing damaged or upgrading concrete structures by using fiber-reinforced composites. 
For example, several sessions were devoted to this subject at a recent International SAMPE Symposium and Exhibition, Long Beach, California [1]. The use of composites is natural since the repairing composites tend to be thin laminates that are easily bonded to damaged concrete structures made from cylindrical and flat surfaces in general. Different methods for designing and analyzing thin laminates have been developed and are available in many computer codes. Recent research demonstrates that damaged concrete structures and their repairing composites can be simulated simultaneously by composite mechanics, which is available in some of those computer codes (Mital et al. [2] and Mital et al [3]). By using composite mechanics, we can represent any concrete structural section by assuming that it consists of several layers through its thickness. In so doing, we take advantage of all the features available in computer codes for composite mechanics-for example, ICAN (Integrated Composite Analyzer) (Murthy et al [4]). The objective of the proposed paper is to describe those features and attendant computer codes, and illustrate their application to select reinforced concrete structural sections and structures. The composite mechanics are described briefly. Then, it is applied to select structural sections and to select structures (a special arch and a dome). Note that the results presented herein are computational. Comparisons with other methods and concrete code requirements are included in the references cited.

\section{Composite mechanics}

Composite behavior is simulated by assuming that the composite consists of several layers (plies) through its thickness. The plies include both fiber and matrix. Theoretically, we can represent any concrete structural section by assuming that it consists only of several layers through its thickness where: (1) most layers consist only of concrete (matrix); (2) one or two layers consist of concrete and steel R-bars (matrix and fibers); (3) one or several layers of the composite repair laminate. Composite mechanics is natural, then, since we can represent concrete structural sections as layers and also composite laminates as layers. By so doing, we take advantage of all the features available in computer codes for composite mechanics_-for example, ICAN (Murthy et al. [4]).

\section{Brief description of ICAN features}

A brief description of ICAN features is instructive, because it demonstrates its versatility and ideal application to reinforced concrete. ICAN evolved from research conducted in composite micromechanics and macromechanics over the last four decades at NASA Glenn Research Center. The primary goal of that research is to develop composite mechanics theories and structural analysis methods that range in scale from micromechanics to structural analysis in one integrated code, see figure 1 (Murthy et al [4]). The micromechanics theories are represented by simplified equations that have been corroborated by detailed three-dimensional finite element analyses (Caruso and Chamis [5]). ICAN is designed to carry out a comprehensive analysis including the hygral, thermal and 
mechanical properties/responses of multilayered continuous fiber reinforced polymer matrix composites. The analysis contains the essential features required to obtain the material properties integrated through the thickness to effectively design structural components made from fiber composites. It can analyze standard composites, i.e., composites consisting of one type of fiber in a matrix forming a ply lamina or a layer. In addition to that, the code can also analyze an interplay or intraply hybrid composite system. This is a useful feature because different types of R-bars can be included in the same section. These layers are then arranged with prescribed orientations to form a composite laminate. The micromechanics equations in ICAN take into account the effects of temperature and/or moisture gradients through the thickness. This feature can be very useful in modeling curing of concrete or degradation in moist-type environments. However, within each layer, the temperature or moisture is assumed to be constant. ICAN includes a dedicated databank of constituent material properties of commonly available fibers and matrices, and also allows the user to build, in a very user-friendly manner, a database of new material properties when they become available. The user needs to specify only the code name of the constituent and the code gets all the appropriate material properties from the databank.

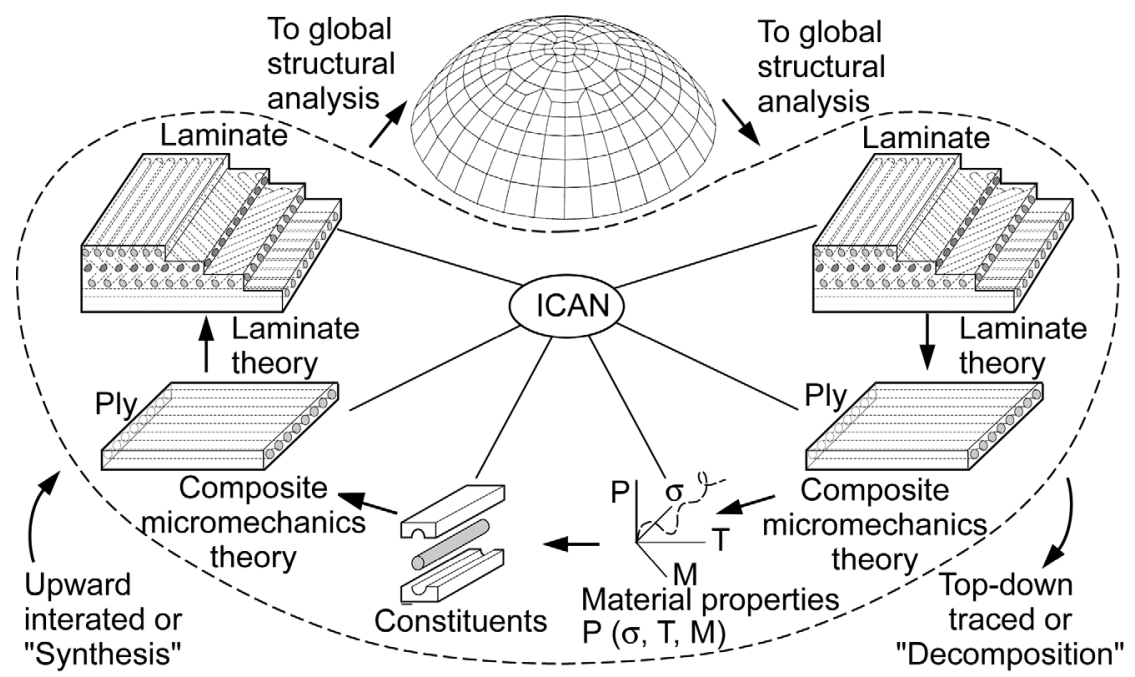

Figure 1: CODSTRAN simulation cycle.

Input to ICAN includes composite geometry, i.e., the ply or the layer lay-up and fiber volume ratios, thicknesses and the orientations of the layers, code names for the constituent materials, factors reflecting the fabrication process and the loading conditions. ICAN performs a micromechanics and macromechanics analysis of the laminate, ICAN output includes the various ply and composite properties, composite structural response, and composite stress analysis results with details of failure. Additional features unique to ICAN include ply stress-strain relations, stress concentrations around a circular hole, free-edge stresses, material properties 
input for finite element analysis using MSC/NASTRAN and other general purpose finite element codes, failure loads based on maximum stress criterion and laminate failure stresses based on first-ply failures, etc. The output from the program can be tailored to specific needs of the user by choosing the appropriate options in the input file. Integration of ICAN with general-purpose finite elements structural analysis is shown schematically in figure 1 and will be discussed further in a later section when structural progressive fracture is simulated. The detailed application of ICAN to concrete is described Mital et al. [3].

\section{Composite enhanced reinforced concrete structural sections}

The concept is first demonstrated by applying it to a one- and two-way reinforced concrete section. Then it is applied to a special arch and a dome both made from reinforced concrete.

The section investigated is $\mathrm{h}=25.4 \mathrm{~cm}$ (10 in.) deep by $\mathrm{b}=15.24 \mathrm{~cm}(6 \mathrm{in}$.) wide. It is one-way reinforced with $1.27 \mathrm{~cm}(0.50 \mathrm{in}$.) diameter steel reinforced bars (fig. 2(a)). The section is represented by plies as shown in figure 2(a). For this application, it was assumed that the section was damaged (cracked at the bottom) and was subsequently repaired by unidirectional composite laminates. The properties assumed for the different materials were: concrete modulus = 20.68 GPa (3 Mpsi), strength $=2.07$ MPA (300 psi) tension, 20.7 MPa $(3,000 \mathrm{psi})$ compressions; steel modulus $=206.8 \mathrm{GPa}(30 \mathrm{Mpsi})$, yield strength 137.9 $\mathrm{MPa}(20,000 \mathrm{psi})$ tension. The area of the reinforcing steel bars is $4.5 \%$ of the concrete structural section $(\mathrm{h} \times \mathrm{b}$, fig. $2(\mathrm{a}))$. The section is enhanced with E-Glass/Epoxy with a 0.55 fiber volume ratio, composite modulus $=38.0$ $\mathrm{GPa}(5.5 \mathrm{Mpsi})$ and tensile strength $=1.38 \mathrm{MPa}(200 \mathrm{ksi})$. The results obtained for the one-way section are plotted in figure 3 . As can be seen, the enhancement is substantial (two times) for a relatively small composite thickness and increases linearly with composite thickness. Comparable results for the two-way slab (fig. 2(b)) are plotted in figure 4 . The enhancements are even greater than for the oneway slab.

(a)

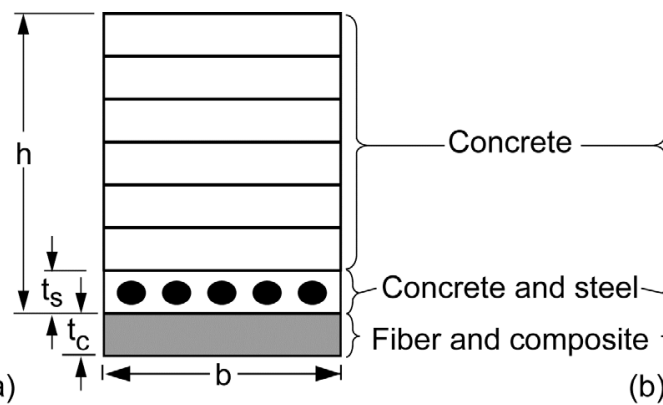

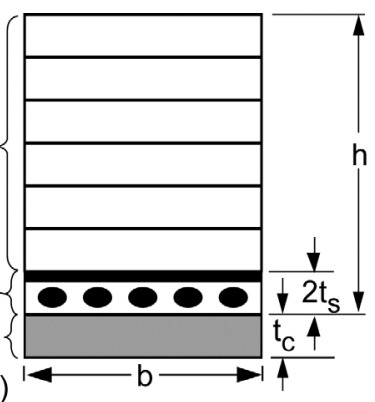

Figure 2: Composite repaired/enhanced concrete. Infra structure sections. (a) One-way-reinforced section. (b) Two-way-reinforced section. Notes: percent steel $=\left(\mathrm{A}_{\mathrm{s}} / \mathrm{hb}\right) \times 100$, equivalent fiber volume ratio for steel ply $=\mathrm{A}_{\mathrm{s}} / \mathrm{t}_{\mathrm{s}} \mathrm{b}$, composite thickness ratio $=\mathrm{t}_{\mathrm{c}} / \mathrm{h}$. 


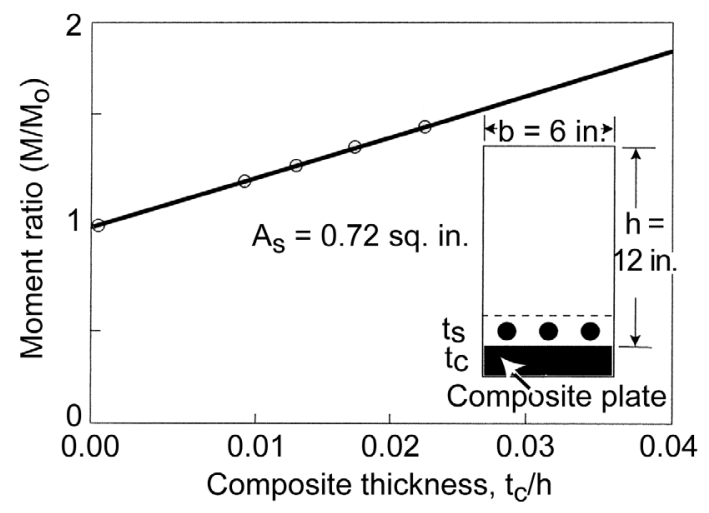

Figure 3: Beam enhanced design moment by composite, E-G/E; 0.55 FVR.

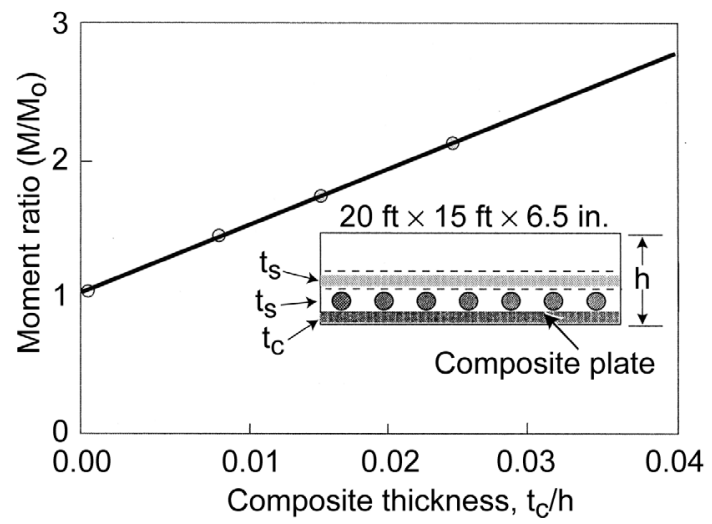

Figure 4: Slab enhanced design moment by composite, E-G/E; 0.55 FVR.

\section{Composite enhanced special reinforced concrete arch}

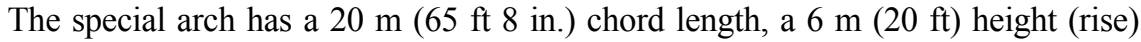
and a thickness of $25.4 \mathrm{~cm}$ (10 in.). The structural section is reinforced with twoway steel at the inner, outer, and mid surfaces. The total volume ratio of the steel in the section is $0.67 \%$. The arch is $26.0 \mathrm{~cm}$ (10 ft 3 in.) wide at the base and $32 \mathrm{~cm}$ (1 $\mathrm{ft} 7 \mathrm{in}$.) wide at the crown. A finite element model schematic of the arch and its structural sections are shown in figure 5. The arch is first evaluated without composite enhancement for two different load conditions; concentrated load at the crown and uniform pressure. Subsequently, it is re-evaluated with composite enhancements. The load carrying capacity of the reinforced concrete arch (without the composite enhancement) is determined incrementally by progressive fracture by using CODSTRAN (Chamis et al. [6]). The concentrated fracture load obtained by using CODSTRAN is $172.4 \mathrm{KN}$ (38.8 Kips) while the collapse pressure is 
$0.019 \mathrm{MPa}(2.8) \mathrm{psi}$. The CODSTRAN results for progressive fracture are show (fig. 6) for the concentrated load and in figure 7 for the uniform pressure. Two curves are plotted in each figure, one is for the accumulation of progressive damage and the other is for the vertical displacement at the crown. Note both of the curves are normalized by their respective maximum values as noted in those figures. The important observations from the curves in figure 6 are: 1) the crown displacement curve is smooth while 2) the cumulative progressive fracture is very non-smooth. The deviations from non-smooth indicate discontinuities (jumps) in the damaged volume where load magnitudes for damage initiation, slow growth, and rapid propagation to fracture are easily identifiable. Examining the curves in figure 7 , it is seen that the vertical displacement is smooth and nonlinear, and the progressive damage accumulation is smoother than that for the concentrated load. However, pressure at which damage initiation, slow and rapid progression to fracture occur, are readily identifiable.

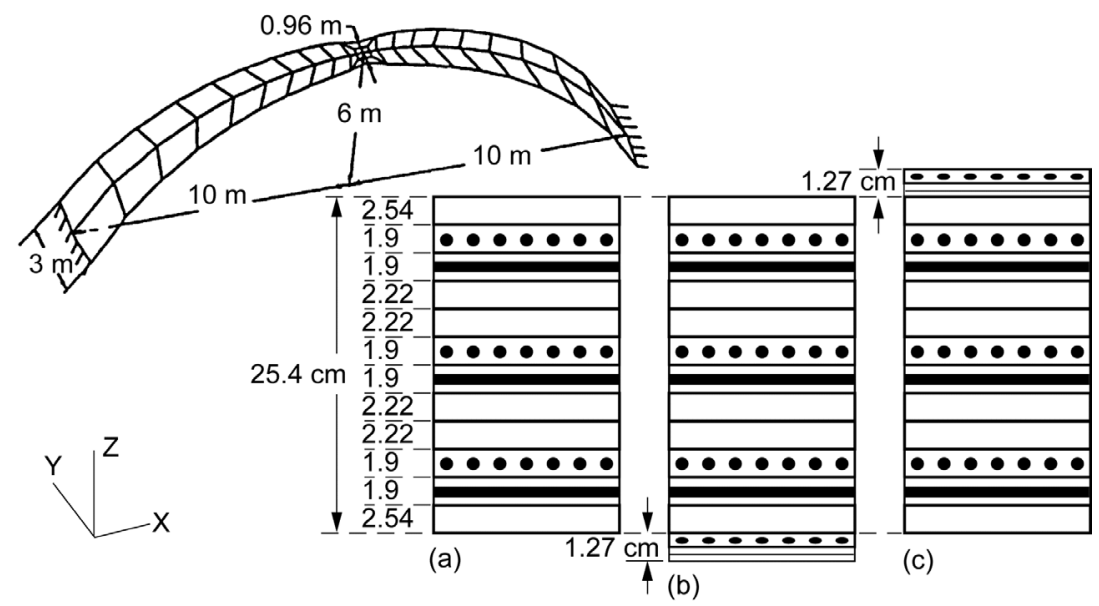

Figure 5: Arch reinforced concrete structure (structural section, reinforced concrete arch with composite enhancements). (a) Unenhanced. (b) Enhanced at bottom. (c) Enhanced at top.

The degradation of structural performance of the arch with respect to other structural performance variables such as frequencies and buckling loads can be readily evaluated at the end of each load increment when the damaged structure is in equilibrium with the applied external loads. For example, the degradation of the concentrated buckling load of the arch is shown in figure 8 , and for its first four vibration frequencies is shown in figure 9. As can be seen in figure, the buckling load starts to degrade with damage initiation (fig. 6) is at about $10 \%$ of the fracture load and continues to degrade rapidly with damage accumulation. The degradation of the vibration frequencies (fig. 9) is not as rapid as that for the buckling load. The important conclusion from the evaluation of the special arch is that composite mechanics coupled with finite element structural analysis provide unique capability to evaluate the structural performance of reinforced 
concrete structures. The arch was enhanced by applying composite layers. The composite layers consist of E-glass/epoxy at about 0.55 fiber volume ratio. The layer thickness was $1.27 \mathrm{~cm}$ (0.50 in.). The results for progressive damage and structural fracture are shown in figure 10. Three curves are plotted in this figure. One is the same as that for the un-enhanced arch (fig. 6). The other two are for the composite enhanced load carrying capability of the arch-one on the top surface and one on the bottom surface. As can be seen, the enhancements are substantial when the composite is placed on the bottom surface.

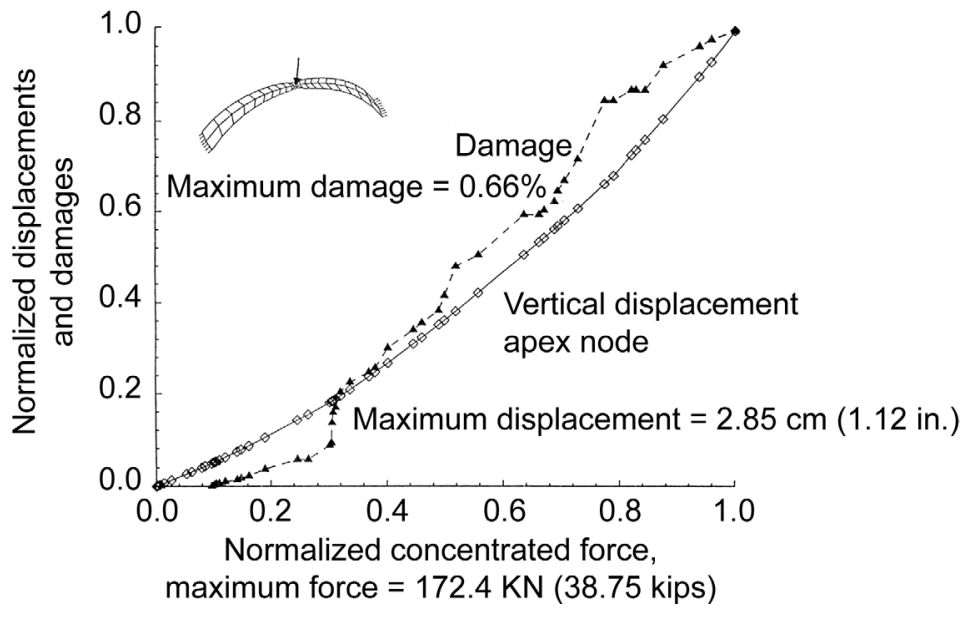

Figure 6: Effect of the concentrated load on the damage and displacements (arch concrete structure).

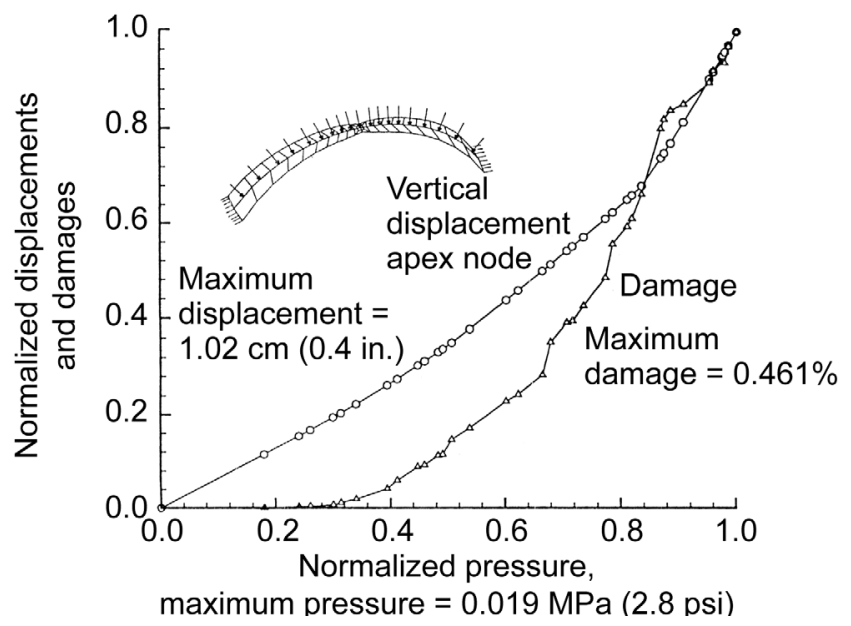

Figure 7: $\quad$ Effect of the uniform pressure on the damage and displacements. 


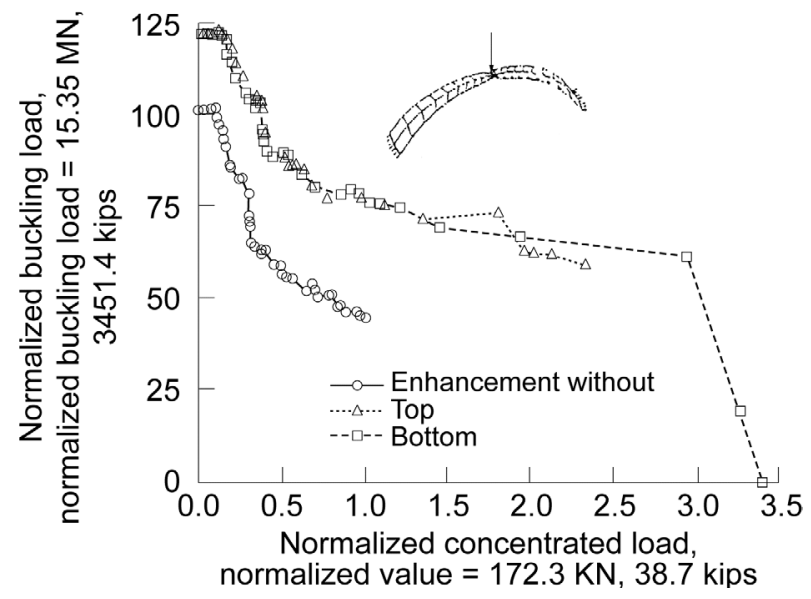

Figure 8: $\quad$ Specialty concrete reinforced arch: concentrated buckling load degradation.

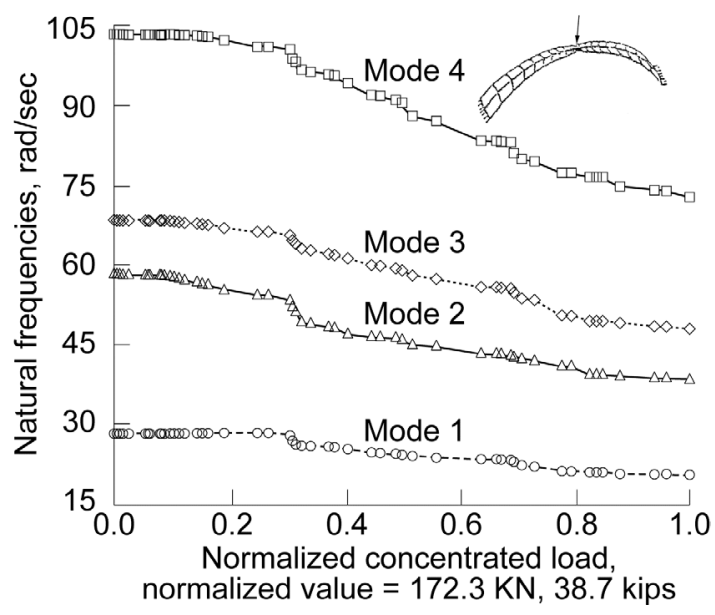

Figure 9: Specialty concrete reinforced arch: vibration frequencies degradation.

\section{Composite enhanced reinforced concrete dome}

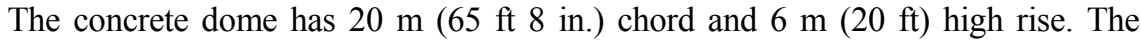
structural section is identical to that for the special arch (fig. 5(b)). A finite element model schematic of the dome is shown in figure 11. The dome is first evaluated without the composite enhancement and then with it. The fracture dome is subjected to two different loading conditions; concentrated load at the crown and uniform pressure load. The fracture load for both conditions is determined by cumulative progressive structural fracture by using CODSTRAN (Chamis et al. [6]). The 
concentrated fracture load for the dome obtained by using CODSTRAN is $310 \mathrm{KN}$ (69.72 Kips) while that for the uniform pressure is $0.34 \mathrm{MPa}$ (4.91) psi. Normalized values of the crown vertical displacement and the damage accumulated are plotted versus normalized force in figure 12 for the concentrated load and in figure 13 for the uniform pressure. Examining the two curves in figure 12, it is seen that the vertical displacement is almost linear to about $30 \%$ from the structural fracture loads damage initiates at about $4 \%$ of the fracture loads. Both damage progression and vertical displacement increase very rapidly as the fracture load is approached. Note that there is less slow damage growth compared to that of the arch. One conclusion from figure 12 is that the dome exhibits limited damage tolerance when subjected to concentrated load at the crown.

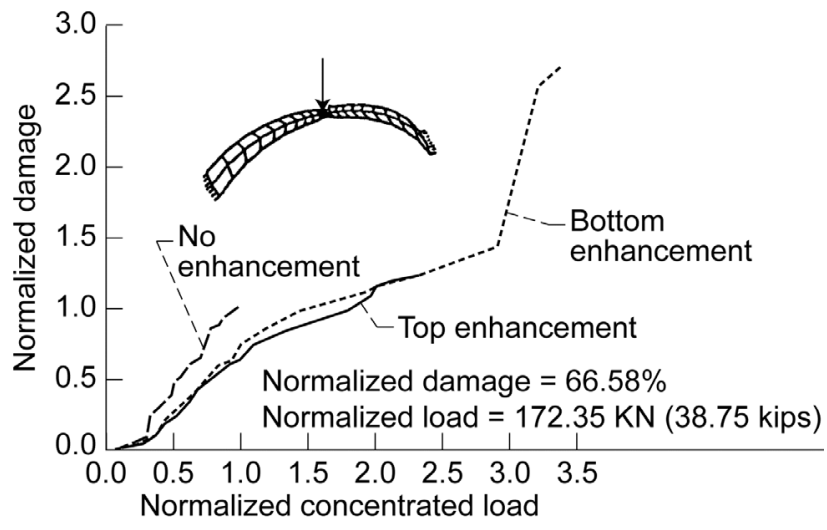

Figure 10: Progressive structural fracture of a concrete-reinforced arch with and without composite enhancements.

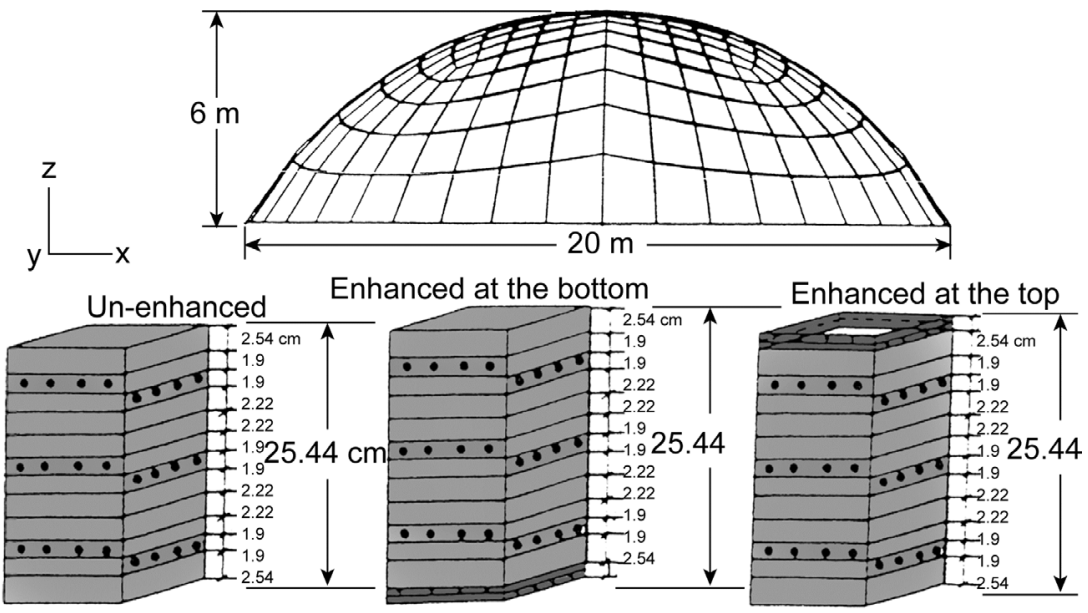

Figure 11: Reinforced concrete dome geometry and structural sections. 


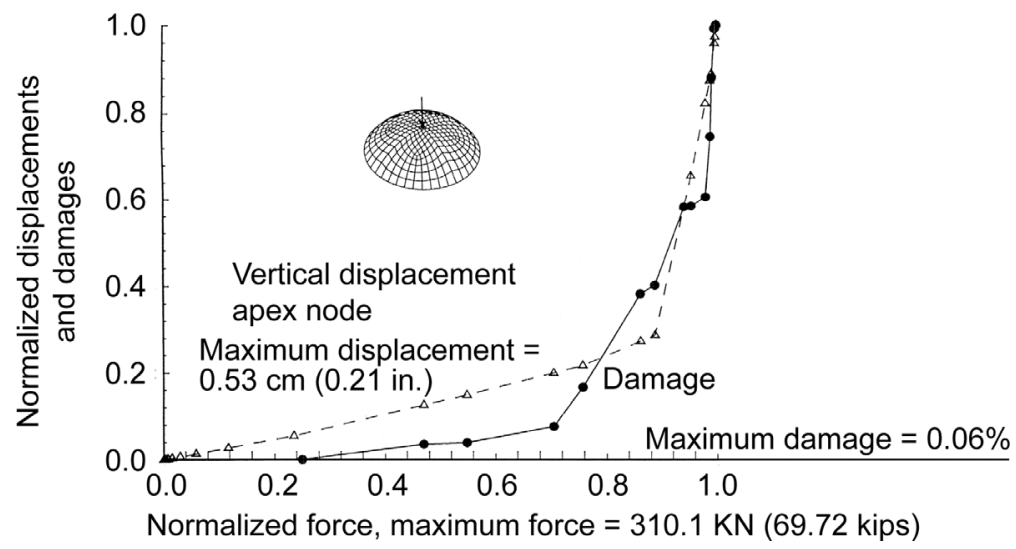

Figure 12: Effect of the concentrated force on the damage and displacements.

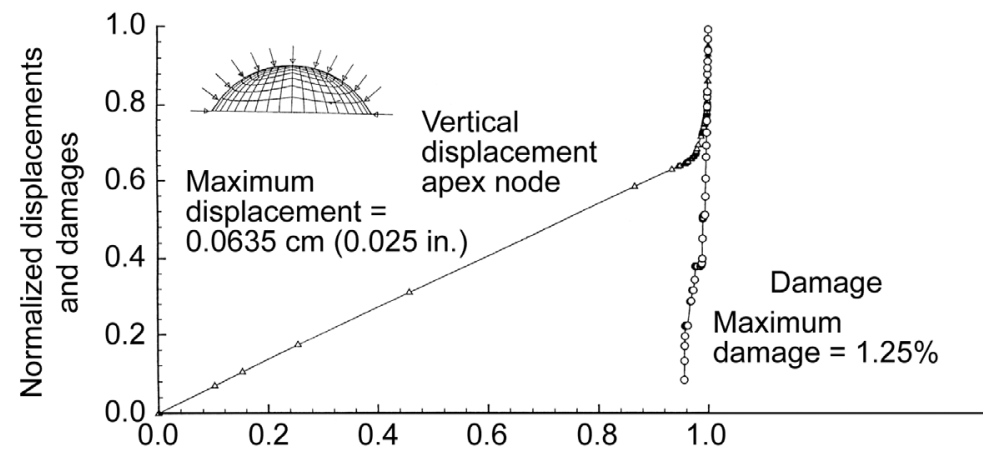

Normalized pressure, maximum pressure $=0.338 \mathrm{MPa}(4.91 \mathrm{psi})$

Figure 13: Dome structure effect of the pressure on the damage and displacements (pressure load, dome reinforced concrete structure).

Normalized values of the crown vertical displacement and the accumulated damage are plotted versus normalized pressure in figure 13. The important observation from these curves is that the dome exhibits linear behavior until very close (within 2\%) to the fracture pressure. Damage initiates sat about $98 \%$ of the fracture pressure and increases very rapidly for the next $2 \%$ to fracture. There is a rapid increase in the crown vertical displacement in the remaining last $2 \%$ of the load. The important conclusion is that the reinforced concrete domes subjected to uniform pressure provide no discriminating information of imminent fracture.

The buckling load of the un-enhanced dome, subjected to concentrated load at the crown, is shown in figure 14 where normalized values are plotted. It is seen that the buckling load is very, very high compared to the fracture load (at least 100 times). It is also seen that buckling load starts degrading at about $23 \%$ of the fracture load. This latter result is interesting because it indicates that progressive damage must initiate at about this value. Re-examination of the curves in figure 
12 reveals that this is consistent with the point at which damage initiates. Note that the buckling load decreases to about $50 \%$ just prior to fracture. The degradation in the first four vibration modes is shown in figure 15. Insignificant or negligible degradation occurs prior to fracture. Apparently, the frequencies are not as sensitive a measure or degradation as is the buckling load.

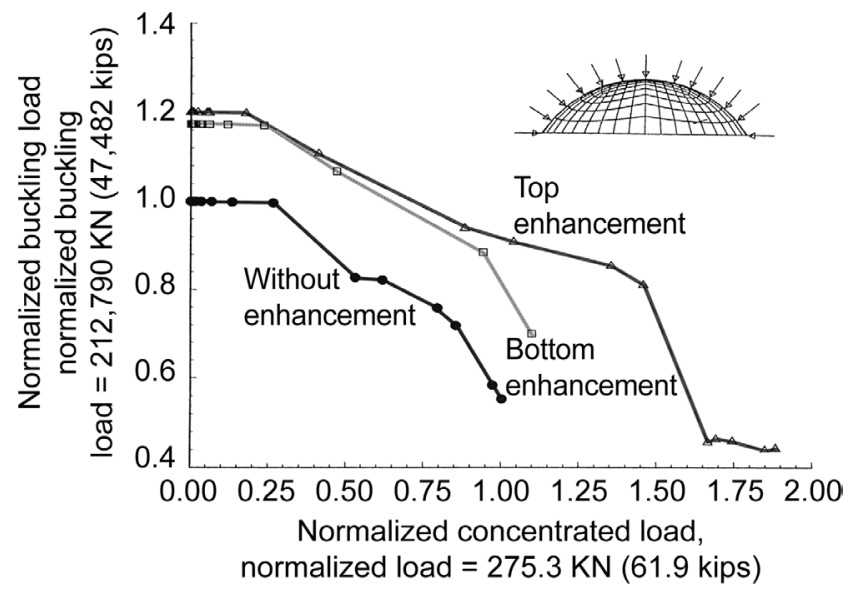

Figure 14: The effect of the damage on the buckling load (concentrated load, dome reinforced concrete structure).

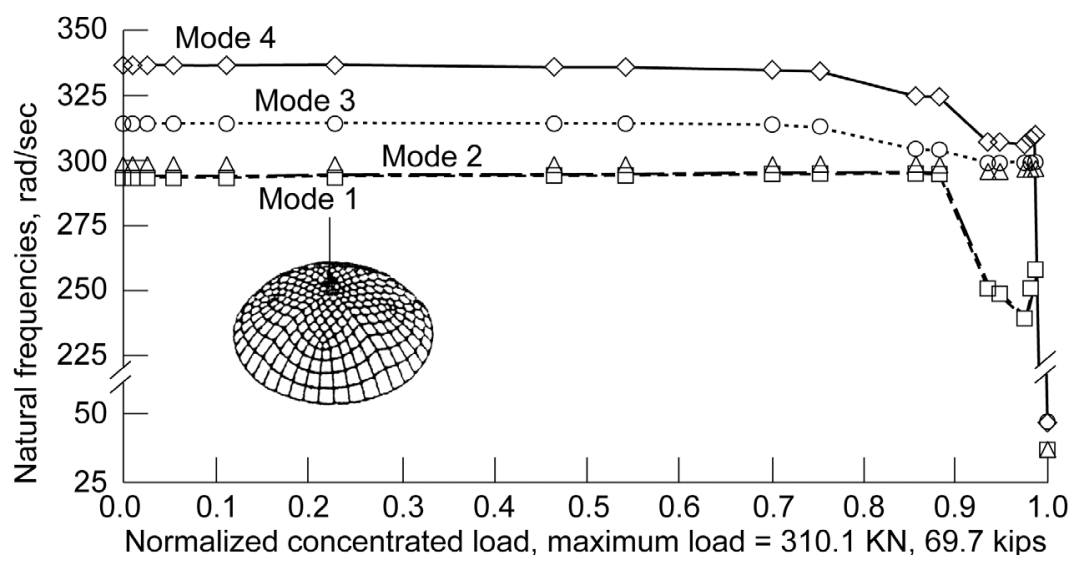

Figure 15: Reinforced concrete dome: vibration frequencies degradation.

The reinforced concrete dome is enhanced with the same composite layers as the special arch. The enhanced results are shown in figure 16 where the damage is plotted versus load for three different cases: un-enhanced, composite enhanced at the top, and composite enhanced at the bottom. It is very interesting to note that the composite enhancement at the top increases the fracture load by twofold, while that at the bottom only about $20 \%$. 
The important conclusions are: 1) the load carrying capacity of reinforced concrete structures can be substantially enhanced by the judicious use of fiber composite layers and 2) computational simulation capabilities which are suitable combinations of composite mechanics and general finite element structural analysis appear to be appropriate to evaluate composite enhanced reinforced concrete structures.

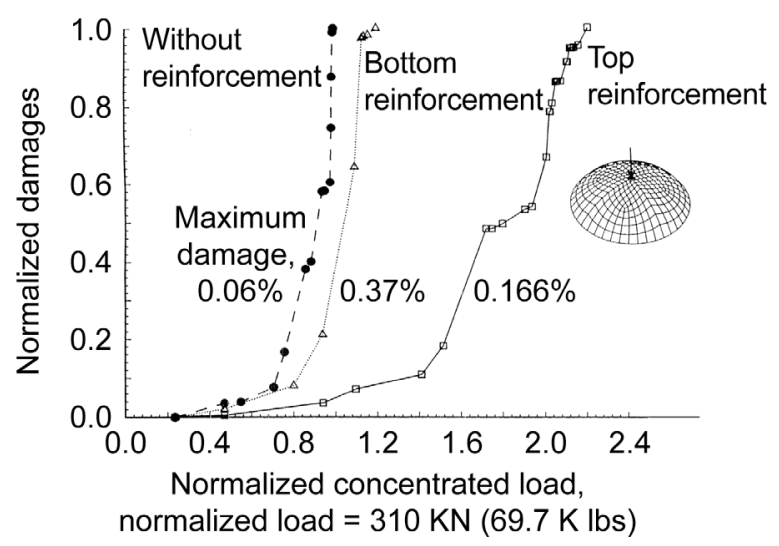

Figure 16: The effect of the applied load on the damage (concentrated load, dome reinforced concrete structure).

\section{General comments}

The results presented previously constitute a relatively small sample of what can be done by using composite mechanics in conjunction with general-purpose finite element structural analysis and composite structural progressive fracture concepts. Obviously, any structural component or assemblies of structural components can be simulated for load carrying capability; fracture loads setting safety factors; designing monitoring devices; scheduling inspection intervals; planning repairs; a composite enhancement that is relatively thin compared to the section and does not introduce asymmetries. Even if it did, composite mechanics and the finite element structural analysis will account for any asymmetry effects on the section performance.

\section{Conclusions}

The important conclusions from an investigation to use composite mechanics for designing composite enhanced structural sections and structures are:

- Composite mechanics can be used to design un-enhanced and enhanced reinforced concrete structural sections.

- Substantial increases in load carrying capacities can be obtained (at least two times) with relatively thin composite layer enhancements. 
- Composite mechanics in conjunction with general-purpose finite element structural analysis and composite structural progressive fracture can be used to obtain the load carry carrying enhancement of reinforced concrete structures. These load enhancements can be as high as three times that of the un-enhanced.

- Structural degradation resulting from progressive fracture can be evaluated for losses in buckling loads and vibration frequencies. Buckling loads are more sensitive to damage than vibration frequencies.

- The damage tolerance of reinforced concrete structures and those with composite enhancements can be evaluated from the progressive structural fracture history as the magnitude of damage sustained from damage initiation to damage for imminent structural fracture.

- The combination of composite mechanics with finite element structural analysis and composite progressive fracture is sufficiently general and can be applied to all type of non-enhanced and composite enhanced reinforced concrete structures.

\section{References}

[1] Several volumes of Spring Conferences, SAMPE, Covina, CA.

[2] Mital, S.K., Gotsis, P.K., and Chamis, C.C., "Laminate Analogy for Composites Application to Infrastructures." Invited paper for the Conference Proceedings of International SAMPE Symposium 42, May 3-5, 1997, Anaheim, CA.

[3] Mital, S.K. and Chamis, C.C., "Thermal and Mechanical Behavior of Particulate Composite Materials, Materials and Design Technology, ASME. PD. 62.275, (1994).

[4] Murthy, P.L.N., Ginty, C.A. and Santfeliz, J.G., "Second Generation Integrated Composite Analyzer (ICAN) Computer Code." NASA TP-3200, (1993).

[5] Caruso, J.J. and Chamis, C.C., Journal of Composite Technology \& Research, Vol. 8(3) 77, (1986).

[6] Chamis, C.C., Murthy, P.L.N. and Minnetyan, L., "Progressive Fracture of Polymer Matrix Composite Structures." Elsevier Science B.V., reprinted from Theoretical and Applied Fracture Mechanics. 25, 1 (1996). 